\title{
Repetition and Graphic Marking in Literary Discourse Studies: Great Expectations
}

\author{
Jingdong Zhong \\ College of English, Zhejiang Yuexiu University of Foreign Languages, China
}

\begin{abstract}
This paper attempts to supply a more visual approach to literary discourse studies, which is based on the analysis of lexical and syntactical repetition aided by graphic marking. The paper discusses the criteria for a good discourse and the elements as a must for a literary discourse. Then it examines the categories of repetition in several disciplines to make a list of linguistic cues for discourse studies and the ways of graphic marking which are adopted to make them more detectable. The efficiency of this approach is observed with a case study of an extract from Great Expectations by Charles Dickens. The paper finds that this approach is direct and efficient.
\end{abstract}

Keywords: discourse; literary discourse; repetition; graphic marking; Great Expectation

\section{Introduction}

"The last two decades in applied linguistics have seen a very considerable growth of interest in discourse analysis," Cook stated that in 1994. That great interest prompted a "major growth industry in modern language study"(Hoey, 1991). Now, after another two decades, this industry is still increasingly flourishing with the adoption of some new terms and the extension of researching areas. Instead of the term of "discourse analysis", some scholars begin to adopt that of "discourse studies", which is defined as"the investigation of relationship between form and function in verbal communication" (Renkema, 2009). This denotes that the fundamental goal of the "industry" of discourse analysis is no great difference from the past and the big concern still lies in "the relation between schemata and specific linguistic choices" What matters is the exploration of more efficient approaches to the studies of such "relationship" or "relation". Besides, literary discourse remains "widely if not universally considered to be one of the most important and the most powerful" among the discourse types as Cook(1994) once states, but the schema theory, whose application to literary studies is emphasized by Cook, receives more attentions in the research work.

This paper attempts to supply a more visual approach to literary discourse studies, which is based on the analysis of lexical and syntactical repetition aided by graphic marking.

\section{Discourse and literary discourse studies}

\subsection{Discourse studies}

Discourse is an act of communication which yields in experiences and texts 
representing them. $\operatorname{Cook}(1994)$ points out the basic claim of the Gestalt psychology of the 1920s is that " a new experience is understood by comparison with a stereotypical version of a similar experience held in memory", namely, schemata or cognitive schemata which consist of the "inferencing procedures" or "shared knowledge of the world" (Cook,1994)as constituent parts. Inspired by such a theory, AI(Artifitial Intelligence) work on text understanding which emerges in 1970s and 1980s attempts to explain "how texts take on unity and meaning for their receivers". It "has been joined with existing approaches to coherence, such as the study of cohesion, text structure" and helped to gain an insight into the formulation of a good discourse.

Text linguist Robert de Beaugrande (1981) states that to qualify as a good discourse a sequence of sentences must meet several criteria for textuality, which is the result of language organization. Halliday and Hasan(1976) term such qualities of organization as texture, which is achieved through cohesive ties. $\mathrm{Hu}$ Shuzhong (2004) points out that the most important qualities of a good discourse are unity, coherence and emphasis. Unity demands that the discourse should express one and only one central thought. Coherence requires that the arrangement of the language units be clear. Emphasis demands that the discourse give the reader a strong impression.

Among the above-mentioned criteria, this paper advocates that situationality, intentionality and cohesion be concerned in priority because they are closely related to constituent parts of "procedures" or "world knowledge"concerning schemata, which Brown and Yule (1983) once discuss exclusively in the chapter of "Coherence in the interpretation of discourse" in Discourse Studies. According to their summary of different discussions about this matter, the activation of schemata involves particularly in situation, thematisation, and organization, which are in fact the elements of situationality, intentionality and cohesion respectively. Situationality denotes a particular context of situation in which a particular intention arises and thus a particular discourse would be produced, while intentionality means that the writer should have the conscious intention of achieving specific goals with his message. As for cohesion, it can be defined as the objective connectivity that is literally detectable in a discourse, which is the observable ways to achieve coherence. In discourse studies these three elements are fundamental, concerning "schemata preserving", "schemata reinforcing" or "schemata refreshing”(Cook,1994).

\subsection{Literary discourse studies}

As far as literature discourse studies are concerned, the elements of cohesion, intentionality and situationality should also be examined in priority, though the description of them may be modified to some degree concerning the speciality of "literary" factors or "literary schemata".

A literary discourse is assumed as the communication between the writer and the reader through artistic language. The writer attempts to express his strong emotions or his particular visions of life and share them with the readers. In the discussion of poetry, one of typical literary discourses, Verdonk(2002)argues that it " does not make direct reference to the world of phenomena but provides a representation of it through its peculiar and unconventional uses of language which invite and motivate, sometimes even provoke readers to create an imaginary alternative world" so as to satisfy themselves at least psychologically. Thus The fundamental function of literary discourse is the 
aesthetic one and in contrast to cognitive schemata of non-literary discourses "literary schemata" belong to aesthetic schemata whose studies greatly concerns the writer's formulation of an influential setting accompanied by an effective atmosphere so as to "provoke" the reader to "enter" the literary situation and the relative mood. So the element of situationality might generally be the initial one to be examined in the process of literary discourse studies. Based on this, two other democratic literary elements fall into consideration, i.e. theme and structure, the counterparts of which in general discourse are theme and cohesion. A literary theme is the main idea, insight or the dominant emotion which is seemingly no difference from a common one, while a literary structure such as the plot development in a novel, a play or a narrative poem might not always a cohesive one, as in the case of stream-ofconsciousness .

Then, how to analyze the language to study the literary elements mention-above efficiently? Or put in another way, how to observe schemata in literary discourse studies concerning elements of theme, context or structure?

Generally, in the studies the mind "stimulated either by key linguistic items in the text", "or by the context, activates a schema, and use it to make sense of the discourse"(Cook, 1994). But what are key items? As we often observe in the discourse, theme often appears repeatedly in the discourse and the intensified description of setting and atmosphere means the repeated using of some key words or sentences, which may also supply a "skeleton" to construct the whole discourse. So devices of repetition are key factors to make a good literary discourse and they can serve as the key to discourse studies. Let's further to elaborate this in the next section.

\section{Repetition and graphic marking}

\subsection{Repetition}

As a figures of speech, repetition denotes the ways of repeating some linguistic items exactly both on the lexical and syntactic level, which are used to produce emphasis, clarity, amplification or emotional effects. However, it excludes some ways of repeating the same structure, which are termed parallelism and climax .

In stylistics, although repetition and parallelism fall into the same category of overregularity, they are different types. Leech(1969) defines repetition as the exact copying of some previous part of text (whether word, phrase, or even sentence) while he states that in any parallelistic pattern there are must be an element of identity and element of contrast, which are "parallel" with respect to their position in the pattern.

Functional linguists Halliday and Hasan(1976) believe that the organization of discourse depends on cohesive ties which are divided into five classes: conjunction, reference, substitution, ellipsis and lexical cohesion. With the exception of conjunction, the rest are "all ways of repeating"(Hoey, 1991). So we may adopt the term of repetition to cover more linguistic features. To avoid the confusion of notion, we'd better do a little more analysis. Lexical cohesion can be classified as sub-classes of reiteration and collocation. Reiteration includes not only the exact repetition but synonymy, antonymy, hyponymy and meronymy. Thus it denotes broader meanings. Collocation is a simply cover term for the cohesion as the result of the cooccurrence of lexical items which are in some way or other typically associated with each other because they tend to occur in similar environment. The cooccurrence of items in collocation leads to at least the recurrence of the same 
context or environment, so we argue that collocation is also a way of repeating.

Hoey (1991) emphasizes the particular lexical repeating types that play more important role in organizing a discourse and modifies the classification of the types of repetition, namely, simple or complex lexical repetition, simple or complex paraphrase. The first two denote items which are exactly or partly repeated but without greater alteration than are entirely explicable in terms of a closed grammatical paradigm such as the singular or plural paradigm. Simple paraphrase typically covers synonymy while complex paraphrase includes antonymy.Thus the notion of repeating is enriched both in types and the functions.

Now let's do the more discussions of repetition in the case of literary discourse, though it might still be assumptions till now. In the process of production, the writer's feelings or thoughts are activated in the setting and he provides a representation of them through the language forms of repetition, while in the process of reading the reader tend to make use of the cues of repeated items to relive the "setting" which may evoke the similar mood and help him to comprehend the the character and the writer's feelings or thoughts.

\subsection{Graphic marking}

All the precedent discussions denote a "repeating"nature with more or less the same psychological base or "schema procedures" lying behind them. Cognitive psychology states that thinking is a "repeating" process in which three human competences of association (by likeness, contrast or contiguity) are intrinsically and naturally involved. Association means connection or linkage. We link item A to item B because they "share" something similar or opposite and they may occur together in a context frequently.
These psychological linkages appear in the forms of some interrelated linguistic devices which reoccur in the discourse to form different types of text-strategic continuity (of time, place, participant, topic and action) so as to make the writer's text "flow".Verdonk (2002)states that "as the observable product of the writer's discourse" the text "in turn must be seen as the process that has created it", so "a reader will search the text for cues or signals that may help to reconstruct the writer's discourse". The repeating items mentioned above make the "flow" of a text visual and thus observable. They can serves as the cues for the reader to recreate the context, to seek the theme and to analyze the structure . In order to make them more observable and easier to be seen and to formulate "schema procedures", we can adopt a set of graphic ways to mark them visually on the reading materials. This is a graphic marking approach to discourse studies. In the next section, the analysis of a fictional extract will be presented as exemplification.

\section{A case study: from Great Expectations}

We take one of the initial paragraphs from chapter 39 in Great Expectation by Charles Dickens as an instance, which might denote the setting due to its position in the discourse:

It was wretched weather (1a); stormy and wet, stormy and wet( $1 b)$; and mud, mud, mud, deep in all the streets(1c). Day after day, a vast heavy veil had been driving over London from the East, and it drove still, as if in the East there were an Eternity of cloud and wind(2). So furious had been the gusts, that high buildings in town had had the lead striped off their roofs (3a); and in the country, trees had 
been torn up, and sails of windmills carried away $(3 b) ;$ and gloomy accounts had come in from the coast of shipwreck and death(3c). Violent blasts of rain had accompanied these rages of wind(4a), and the day just closed as I sat down to read had been the worst of all(4b).

To make the analysis clearer, this extract adopts a set of graphic marking ways: The key nouns and pronouns are in box. Other important lexical items (e.g. verbs, adjectives) are in bold. Items denoting the time and place are in italic. The items supposed to supply cues for the central idea is underlined. In addition, to show the comparison or the contrast more clearly, the nouns denoting the bad weather are in shade in contrast to the ones denoting the human and natural sufferers.

Through graphic marking, we can obtain a visual deep impression that several human and natural sufferers seems to be surrounded and bewildered at the mercy of the bad weather denoted by so many items in bold and shade. It is a good illustration of efficiency of multiple repetition adopted to create a impressive setting. Let's do further analysis.

Sentence(1)catches eyes immediately with the exceptional repetition of stormy and wet and mud. Stormy means to violent wind and heavy rain while wet denotes heavy rain. So stormy is emphasized by wet within the same phrase while the phrase itself is also repeated. Mud is the collocation of stormy and wet. It occurs three times to stress the disgust and the degree of which is intensified by deep and all (all the streets implies the whole area is full of mud). Besides, Sentence(1) is a loosen sentence, which is divided into three parts with two semicolons. The narrator seems low in spirits and thus slow in thinking. Probably he could not help sighing with minor pauses when confronted with the wretched weather.

In sentence(2), Veil refers to mists or cloud. It is reiterated by the synonymy of cloud and the collocation of wind and they reiterate stormy and wet(1b)as collocation. The items of heavy and Eternity denote the density of veil while Day after day and had been driving implies the continuity of the veil. Besides, drove still denotes the motionlessness. All the items serve as the co-reference to reveal the foggy state of the foggy capital.

Sentence(3) exclusively describes of the powerful and destructive gusts which is the synonymy of strong wind(2). Sentence( $3 a)$, (3b)and (3c) denote the depressing situation in the town, the country and the coast respectively. Thus the impoverished area extends from all the streets $(1 \mathrm{c})$ to the whole area. This long sentence include high buildings and roofs as meronymy, roofs and sails of windmills as collocation, shipwreck and death as collocation. The co-occurrence of all these sufferers, including trees reveal the gloomy fact that everywhere everything and everybody is at the mercy of the gusts. This description is greatly enforced by a series of verb phrases: striped off( $(3 a)$, torn up and carried $\operatorname{away}(3 b)$.

In sentence(4), the synonymous items of furious(3a), i.e. violent and rages (4a)are adopted to describe the power of the rain which holds a candle for the devil. At length, the worst $(4 b)$ echoed wretched(1a) with the increase in degree and thus the structure of this discourse obtain a sound feature of repetition.

In short, the multiple repetition of all the items mentioned above efficiently help to create depressive setting in a depressing atmosphere which spreads across the rest of the discourse. As for the schema of the weather contained in this discourse, it is more than a cognitive one concerning some practical matters such as 
weather report. Rather, it is an aesthetic one which brings reader into a concentrated and highlighted small world to experience the protagonist's life and meanwhile "to find a reflection of our conflicting emotions" and thus "to feel reassured" to some degree (Verdonk, 2002).

\section{Conclusion}

With the discussion above, this paper finds that in the process of literary discourse studies we can make good use of the cues of repeated items to relive the "setting" which may evoke the similar mood and help him to comprehend and interpret a discourse. To elevate the efficiency of this process we' $d$ better highlight and visualize these cues through graphic marking. More important, this approach may contribute a lot to the formulation and refreshment of the aesthetic schemata.

However, this study is still a preliminary one, which should cover more literary discourse types such poetry, drama and essay with more substantial instances. The schema theory, concerning the differences between cognitive schemata and aesthetic schemata needs further analysis. And, the categories of repeating items which should be included in the analytic frame and the formulation of a more operable set of graphic marking ways require more examinations and efforts. Anyhow, the author will be satisfied if this paper does offer some insights into the approaches to literary discourse studies and encourages further probes into this area.

\section{Acknowledgement}

A project supported by Zhejiang Yuexiu University of Foreign Languages Project ( ID JG1205 ).

\section{References}

[1] Brown, G., \&Yule, G. Discourse Analysis. Cambridge: Cambridge University Press, 1983.

[2] De Beaugrande, R., \& W. Dressler. . Introduction to Text Linguistics. London: Longman Group, 1981.

[3] Dickens,C.Great Expectation. Beijing: China Translation and Publishing Corporation, 2010.

[4] Halliday, M.A.k., \& Hasan, R. Cohesion in English. London: Longman Group, 1976.

[5] Hoey, M. Patterns of Lexis in Text. Oxford: Oxford University Press, 1991.

[6] Hu, S.Z.(Ed.) Modern English Rhetoric.Shanghai: Shanghai foreign Language Education, 2004.

[7] Leech, G. N., \&Short, M.H. Style in Fiction. London : Longman Group, 1981.

[8] Renkema, J. Introduction to Discourse Studies. Shanghai: Shanghai Foreign Language Education Press, 2007.

[9] Shao, J.D.,\& Bai, J.P. (Eds.) An Introduction to Literature. Shanghai: Shanghai Foreign Language Education Press, 2002.

[10] Thompson,G.Introducing Functional Grammar. London: Edward Arnold, 2000.

[11] Verdonk,P. Stylistics.Oxford: Oxford University Press, 2002.

[12] Yu, X.Y. Stylistic Study on English Poetry. Beijing: Science Press, 2007. 